\title{
Corpus-based Evaluation on Instrumental Texts in Textbook
}

\author{
Mengqi Zhang ${ }^{1}$, Wenzhong Zhu ${ }^{2} \&$ Muchun Wan ${ }^{3}$ \\ ${ }^{1}$ School of English for International Business, Guangdong University of Foreign Studies, China \\ ${ }^{2}$ School of Business, Guangdong University of Foreign Studies, China \\ ${ }^{3}$ School of English for International Business, Guangdong University of Foreign Studies, China \\ Correspondence: Zhang Mengqi, School of English for International Business, Guangdong University of Foreign \\ Studies, No.2 Baiyundadaobei, Guangzhou 510420, P.R. China. E-mail: 774703228@qq.com
}

$\begin{array}{lr}\text { Received: July 6, 2018 } & \text { Accepted: July 24, } 2018 \quad \text { Online Published: August 20, } 2018 \\ \text { doi:10.5539/hes.v8n3p104 } & \text { URL: https://doi.org/10.5539/hes.v8n3p104 }\end{array}$

\begin{abstract}
Instrumental texts, as an important part of the textbooks, play an important role in organizing the teaching content and the teaching activities, facilitating the communication of the teacher, students and textbooks. Therefore, it is of great theoretical and practical significance to study and evaluate the instrumental texts of the textbooks. The instrumental texts in Market Leader is adopted as the research object. Content analysis and corpus analysis are applied in this paper. By retrieving their salient lexical and semantic patterns which are further associated with some modern concepts in ESP education, the book is evaluated from the perspective of cognitive strategy, learning styles, the relationship between teaching materials and learners and contextualized language instructions. The results of this study are as following: 1) Teaching notions can be reflected from the instrumental texts. 2) Cooperative learning and learners-centered approach are well shown in this book. Cognitive thinking and situation creation are relatively weak in this book.
\end{abstract}

Keywords: instrumental texts, cognitive strategy, learners-centered approach

\section{Introduction}

English teaching has been received wide attention from all sectors of society. Teaching materials, as essential tools and resources in the process of teachers' teaching and students' learning, play significant and indispensable role in English teaching, also providing important guidance for English teaching concept. For learners, the textbooks are the main inputting sources and learning directors in class; for teachers, the textbooks are the foundation and main tools in the process of teaching (Mukundan \& Ahour, 2010). Therefore, the work of writing and revising teaching materials has never stopped.

The evaluation of English textbooks has been developed for many years, however, there are not so many studies when it comes to instrumental texts. Instrumental texts, as an important part of teaching contents and teaching discourse, are essential segments in performing teaching activities effectively, connecting teachers, leaners and teaching activities. Education and teaching idea permeated in the textbooks can also be reflected in instrumental texts directly and comprehensively. And some merits and demerits can also be shown in instrumental texts. The study on instrumental texts make contributions to the multi-dimensional analysis of the education and teaching idea. It is necessary to analyze the instrumental texts in the textbooks, which is meaningful and practical for the textbook writing and revision in the future.

This paper discussed the reasonability of the instrumental texts in the textbook, Market Leader, on the basis of learner-centered approach. The aims of this paper are to analyze how the instrumental texts in this book guide learners' and teachers' thinking activities and examine whether the texts are learner-oriented. Modern corpus linguistics research with the functions of concordance and word list is a scientific way to extract quantitative evidence (Concord, 2002). In addition, textbooks, with the carrier of language and words, are suitable for being evaluated by the means of corpus. Corpus-based methodology is applied in this paper, and a corpus of instrumental texts are established. Words, concordance and sentence patterns in the target texts are analyzed through the establishment of corpus and the application of retrieval approaches of computers frequency-driven to extract the characteristics of linguistic forms and semantic meaning, and finally the education idea, teaching objectives and teaching method of the instrumental texts are deduced to evaluate some suggestions of designing instrumental texts $(\mathrm{He}, 2007)$. With the rapid advance of computer technology, it has become a new trend that 
English teaching materials are analyzed by the means of corpus and other tools.

The evaluation of English textbooks has been developed for many years, however, there are few studies when it comes to the evaluation of cognitive thinking shown in instrumental texts. After searching the existing database, there are many researches analyzing teaching materials through corpus. Ljung (1990) analyzed the vocabularies, stylistic features and cultural characteristics. Zhao and Zheng (2006) summarized previous research on textbook evaluation and found that traditional analysis of textbook evaluation system was mainly established on qualitative analysis. Quantitative analysis has always been a weakness in textbook evaluation. However, few literatures evaluating teaching materials from the perspective of instrumental texts with the aid of corpus tool. Therefore, it is necessary to do some research on instrumental texts to fill the gap. Instrumental texts are analyzed with the aid of corpus which increases the objectivity of the assessment of the textbook. This study can shed some light on the future study of textbook evaluation.

Two hypotheses have been put forward: 1) The instrumental texts can reflect the teaching notions; 2) The comprehensive understanding and proper use of the instrumental texts can help to improve the teaching and learning effectiveness.

Three questions are answered in this paper:

(1) What are the teaching notions reflected in the instrumental texts?

(2) Whether do the words used in instrumental texts accord with learners-centered approach?

(3) How to make some adjustments to make best use of the instrumental texts

\section{Literature Review}

\subsection{Previous Research of Instrumental Texts in English Teaching Materials}

Instrumental texts refer to the mandatory and explanatory words in organizing teaching contents and teaching activities, which guide teachers how to teach and also reveal the patterns, methods and strategies of learning foreign language (Ellis, 2010). Biber (2002) introduced basic research methods based on corpus. Zhang and He (2009) investigated and compare the high-frequency words, grammar and sentence patterns of instrumental texts in two versions of English teaching materials by means of corpus. It finds that some mental words are repeatedly used in instrumental texts to guide learners to use their brains to learn English. Some behavioral verbs are also used to cultivate learners' hands-on ability, He and Huang (2011) studied the changing of model verbs and important sentences used in instrumental texts in the new and old English textbooks, finding that the choice of attitude vocabularies appears to be significantly weakened. The authors of the textbooks tend to use a deliberative or suggested tone for the learners. Chen (2015) analyzed the noun clauses in instrumental texts and exercises designs through corpus research method. To sum up, all studies on the instrumental texts are related to grammar and vocabulary. And they all applies corpus research method. Therefore, this study also studies instrumental texts with the aid of corpus.

\subsection{Previous Research of Instrumental Texts on Teaching Concepts}

He (2007) adopted corpus research and discourse analysis to analyze education and teaching ideas shown in the instrumental texts of high-school English textbooks after English curriculum reform in China. A batch of characteristic and representative instrumental texts are summarized through analyzing the frequency of some typical words with the combination of semantic classification method and concordance analysis mode, which is beneficial to adjust the relationship between teachers and students and improve teaching situation and learning mode. Chen (2010) compared the instrumental texts of high school English teaching materials between old edition and new edition on the basis of presupposition theory, exploring how new teaching ideas are displayed in the new edition. Tomlinson (2013) pointed out that instrumental texts have an irreplaceable effect in teaching materials. Learners can improve the effectiveness and efficiency of practice and activities only if they understand the instructions. Thus, previous studies are rarely concerned the words used in instrumental texts accord with learners-centered approach and the relationship between learners' cognitive thinking and instrumental texts to evaluate the reasonability of the textbooks.

With the development of computer technology, it is quite easy for corpus building. We can easily get some important data about a complete set of teaching materials through the corpus, especially some specific vocabulary statistics (Conrad, 2002; Wang \& Yang, 2012). The use of corpora-collections of written and spoken texts stored on a computer is becoming an increasingly influential procedure in the promotion of language learning, and nowhere is this influence more apparent than in English for Specific Purposes (Hewings, M., 2012). 


\section{Research Framework \& Research Method}

Bloom's team put forward six-level "cognitive field" of Taxonomy of Educational Objectives, that is, memorizing, understanding, using, analyzing, integrating and assessing (Anderson, 2009). Students' level of cognition can be shown from the design of the teaching activities. Therefore, the design of instrumental texts should not only reflect the requirements of students in different levels, but also show whether the needs of students are satisfied in different levels. The guidance and orientation of cognitive thinking can be reflected obviously in instrumental texts.

The content and the dimension of this research mainly refers to the relevant theory put forward by He (2007) --the evaluation of teaching materials is mainly from the relationship between teaching and teaching theory, the relationship between teaching materials and syllabus, the relationship between teaching materials and learners and exercise designing. Therefore, with the reference to the relevant study of He (2007), four research contents and dimensions are shown in this paper.

The following is the research framework for this paper:

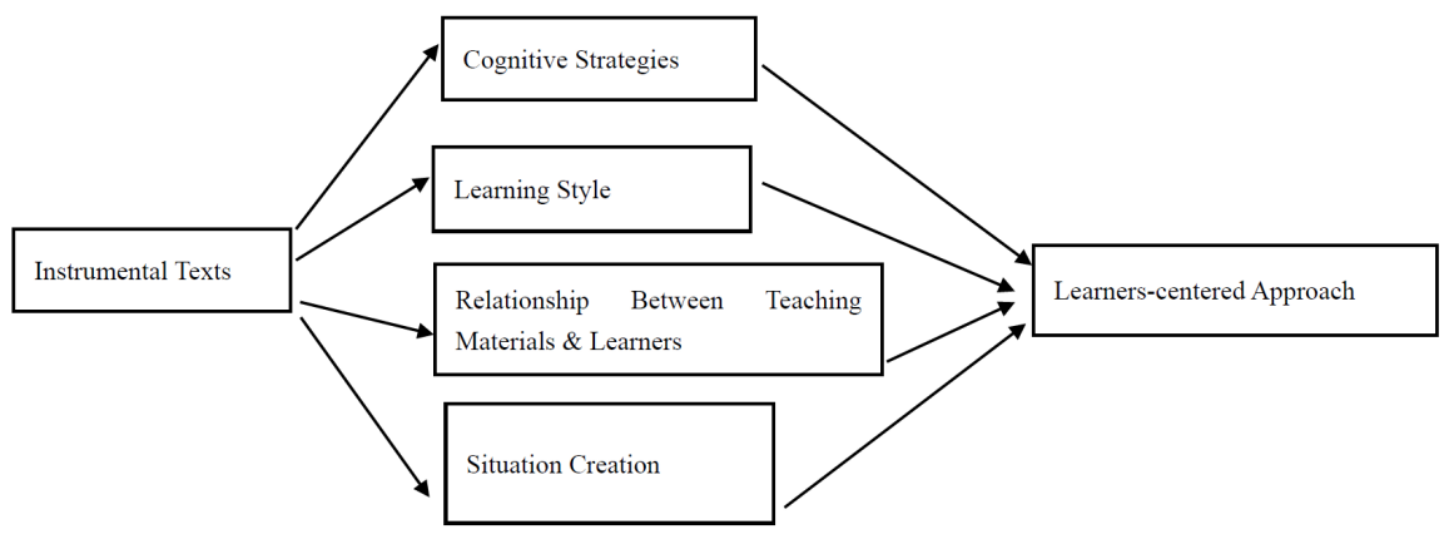

Market Leader 3rd Edition Extra, published by Pearson English Languages Teaching, is a five-level English course for students who want to learn English and learn about business, and for business people who want to advance their careers. Market Leader (4) is adopted as the research materials of this study. The research target is the instrumental texts of the book. Antconc 3.4.1 is applied as an auxiliary tool to the text analysis. Altogether 11947 words tokens are collected as the database of the paper. Data collection and data analysis, quantitative and qualitative methods are applied in this paper in order to carry out a comprehensive study of the instrumental texts. Verbs and Nouns are received attention because nouns or noun phrases are the most commonly used in describing the targets and results of languages; while verbs or verb phrases are the most commonly used in describing the actions and processes of doing, especially the verbs expressing the process of perception and cognition (Krathwohl, 2002).

\section{Analysis \& Results}

\subsection{Cognitive Strategies}

According to Bloom (2009), there are six levels of teaching activities, that is, memorizing, understanding, using, analyzing, integrating and assessing, which is directly associated with learners' cognitive thinking. He (2007) pointed out that learners' higher level of cognitive thinking should be received attention in the design of instrumental texts. He (2007) mentioned that the main mental words involved in instrumental texts are think, imagine, guess, feel, opinion, believe, change, consider and views.

Referring to the above views, "think, imagine, consider, comment, etc." are selected as the retrieval items. 
Table 1. Retrieval Frequency of Mental Words

\begin{tabular}{lll}
\hline & Retrieval Items & Frequency \\
\hline 1 & Think* & 35 \\
2 & Explain* & 12 \\
3 & Consider* & 7 \\
4 & Feel*|felt & 2 \\
5 & Comment* & 1 \\
6 & Predict* & 1 \\
7 & Imagine* & 1 \\
8 & Opinion* & 1 \\
9 & Guess* & 0 \\
\hline
\end{tabular}

According to table 1 , it is found that "think" is the most commonly used word in mental words. Ranking the second is "explain". The rest have low frequency. Therefore, the subjects and objects collocating with "think" in its concordance are stepped into observation and analysis. Here is a part of the concordance:

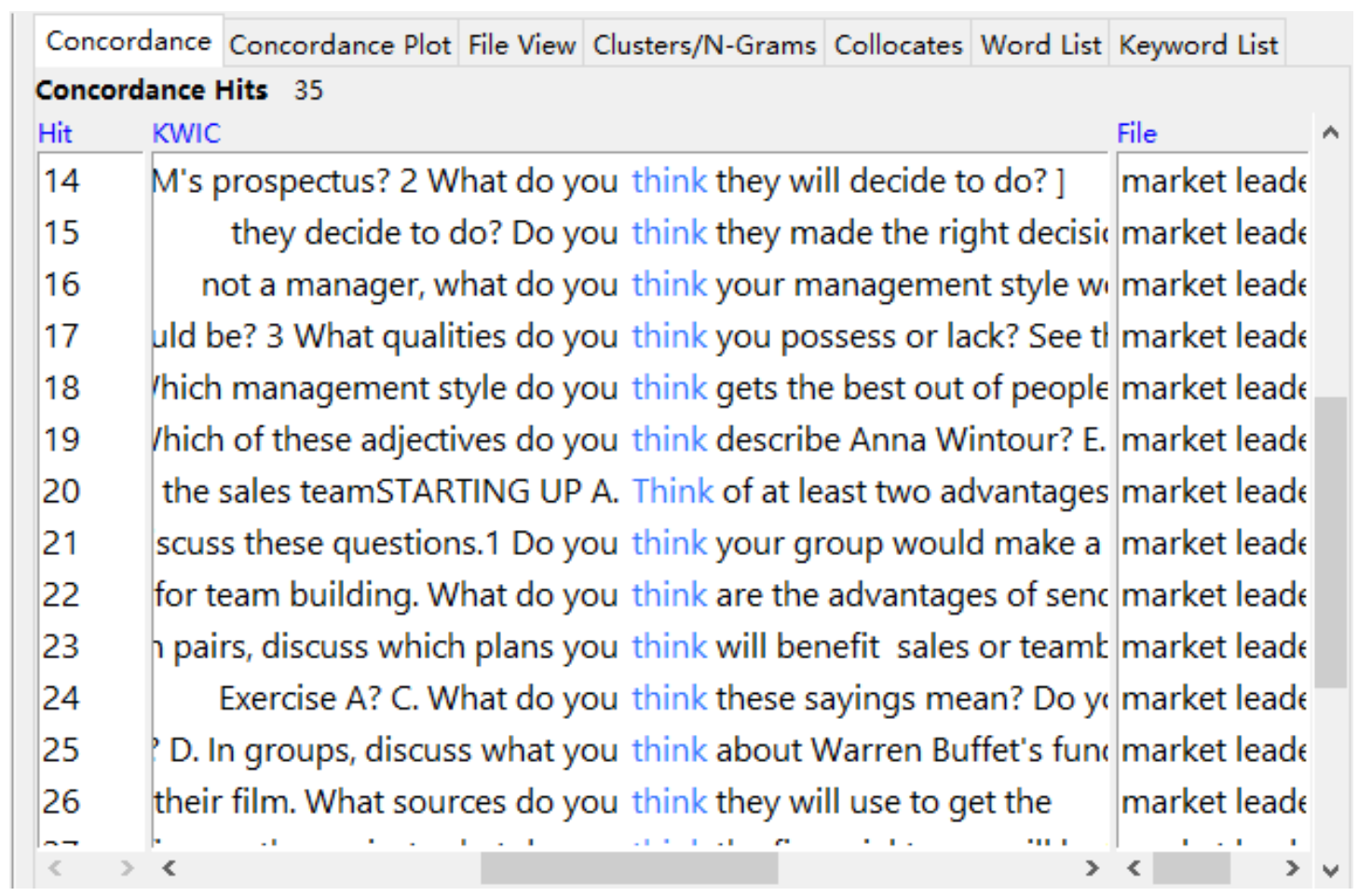

Figure 1. Concordance of THINK

According to Figure 1, it can be seen that the key sentences structure of "think" are "do you think...", "think of/about..." to ask for the suggestions and opinions of students. On the basis of the above retrieval results, the author analyzed how did the instrumental texts guide students' thinking. Three aspects are shown as below:

(1) Concrete figures, for example, communicator, manager, Anna Wintour, Warren Buffet;

(2) Abstract objects, for example, problems, technology, crisis, international teams, financial terms, benefits, merger, acquisition, reasons;

(3) Comparative evaluation, for example, advantages and disadvantages, future projects.

On the basis of Bloom's Taxonomy of Educational Objectives (Forehand, M., 2010), all above thinking activities shown in the instrumental texts have achieved a higher level of thinking activity, that is, assumption, explanation, interpretation, analysis and evaluation, which are not only the lower level like pure memory of words. The higher the level of thinking activities are, the better for cultivating and developing students' thinking ability. In addition, it can be seen that the words collocating with "think" carry the meaning of business, like manager, Anna Wintour, Warren Buffet these business people in concrete figures; "financial teams, merger, acquisition 
these business activities in abstract objects, which are consistent with the nature of the book --- market. Therefore, the design of activities is reasonable. However, the number of this kind of question should be increased to better cultivate students' cognitive thinking.

\subsection{Learning Style}

In the way of learning, "cooperative learning" has been emphasized in recent years. It is encouraged that students should learn to discuss, cooperate with other students Johnson \& Johnson, 2009). As for English teaching, cooperative learning plays an irreplaceable role in creating active classroom atmosphere, improving students' confidence in learning, improving the efficiency of solving classroom problems and enhancing the communication among students (Sharan, 1990). "cooperative learning" receives highly attention and praise in recent years. Words that can obviously show the elements of cooperative learning are retrieved to observe to examine whether the textbook reflect the idea of cooperative learning according their frequency and concordance.

Table 2. Retrieval Frequency of Cooperative Learning Words

\begin{tabular}{lll}
\hline & Retrieval Items & Frequency \\
\hline 1 & Discuss* & 54 \\
2 & Group* & 36 \\
3 & Partner* & 14 \\
4 & Share* & 8 \\
5 & Pair* & 3 \\
6 & Together* & 1 \\
\hline
\end{tabular}

From table 2, it suggests that the idea of cooperative learning is fully embodied in instrumental texts, from which "discuss" is the most frequently used with 54 times. Here is a part of the concordance of "discuss":

\begin{tabular}{|c|c|c|}
\hline \multicolumn{3}{|c|}{ Concordance Concordance Plot File View Clusters/N-Grams } \\
\hline \multicolumn{3}{|c|}{ Concordance Hits 54} \\
\hline Hit & WWIC & File \\
\hline 26 & ntrasting management styles.E Discuss these questions. 1 Whicl & mark \\
\hline 27 & EADING Management styles A Discuss these questions.B Work & market lead $\epsilon$ \\
\hline 28 & with adjectives from Exercise E. Discuss these questions. 1 What & market lead $\epsilon$ \\
\hline 29 & terviews: Every three months. I discuss my team's & ma \\
\hline 30 & We want harmonyat all times. Discuss aims with the team and & market lead $\epsilon$ \\
\hline 31 & Dur answers to Exercise B. Then discuss these questions.1 Do yol & market lead $\epsilon$ \\
\hline 32 & te meanings. Then use them to discuss the questions belor & lead $\epsilon$ \\
\hline 33 & om the Useful language box to discuss the problems.Stud & et lead $\epsilon$ \\
\hline 34 & 's plans below. Then, in pairs, discuss which plans you $t$ & et lead $\epsilon$ \\
\hline 35 & if any, should be acted upon. 4 Discuss any other ideas & market lead $\epsilon$ \\
\hline 36 & to complete each definition. C. Discuss these statements. LISATI & market lead $\epsilon$ \\
\hline 37 & What are they? D. In groups, discuss what you think about W & market lead $\epsilon$ \\
\hline 38 & the idioms in Exercise E. G. Discuss these questions. & market lead $\epsilon$ \\
\hline $\operatorname{mon}$ & . n & , . ; \\
\hline
\end{tabular}

Figure 2. Concordance of DISCUSS

It can be seen from Figure II that "discuss" is often shown in imperative sentences often followed by words like "questions, problems", which is helpful for guiding students to explore problems. 


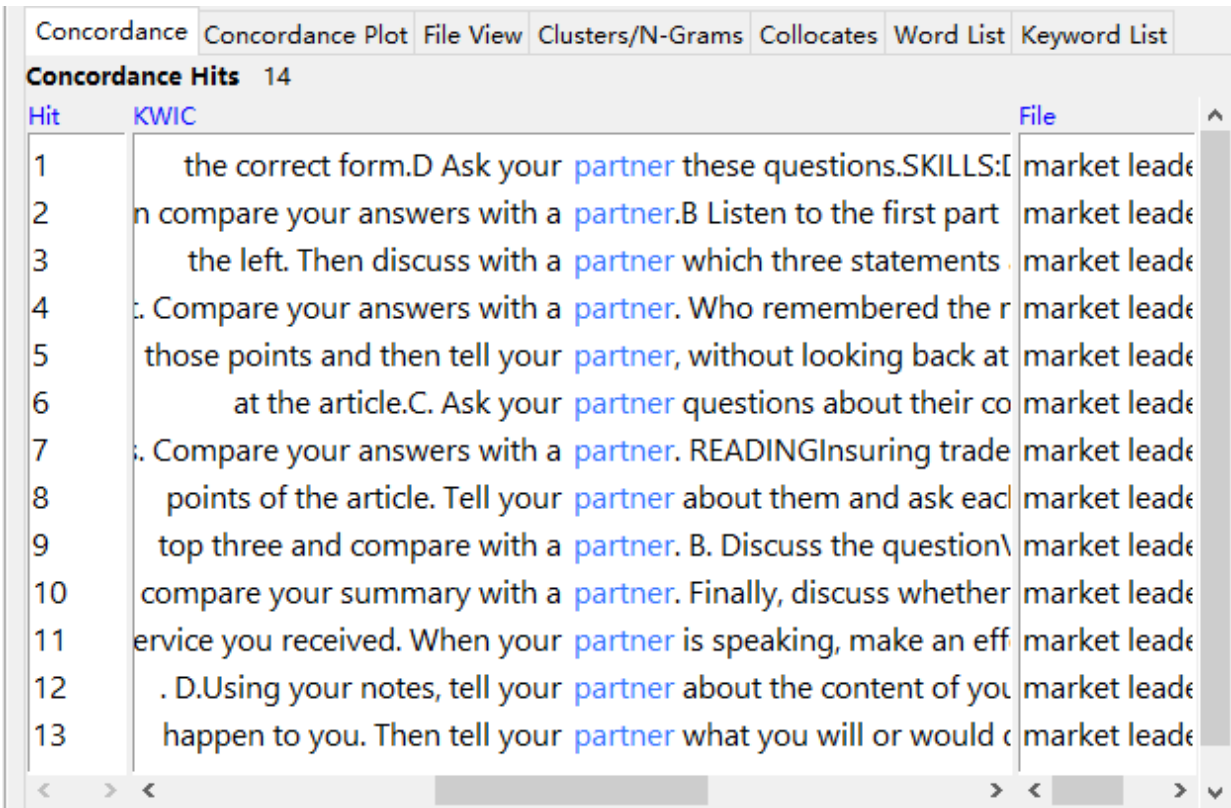

Figure 3. Concordance of PARTNER

"Partner" is one of the representative words to show cooperative learning. In the instrumental texts of Market Leader, "partner" are always used as the objectives of "tell", "ask", which focuses on cultivating the communication skills of learners. In addition, a good market leader should have good communication skills. Thus, the activities designed in the book not only conform to the idea of cooperative learning, but also conform with the aims of the book.

In cooperative learning words, "discuss" ranks the first, followed by "group", and "partner" and "pair" rank the third and the fourth, which reveals that the activities in this book pay attention to multi-person cooperation assisting with pair work. Multi-person cooperation is more likely to simulate a real cooperation environment. And marketing emphasizes group work so that multi-person cooperation activities can better cultivate the learners' cooperative skills in this book.

\subsection{Relationship Between Teaching Materials \& Learners}

It has been emphasized that teachers are no longer the masters of the class but the directors (Bonk \& King, 2012). Students should be the master of their study. "learners-centered approach" can be directly shown in the instrumental texts of the book. Because instrumental texts can guide students in teaching activities directly, showing the status and relationship between the writer and learners and influencing teachers understanding of the relationship between teachers and students in class. He (2007) claimed that the most evident elements showing the relationship between teaching materials and learners are the second personal pronoun "you" and the use of modal verbs.

Table 3. Retrieval Frequency of Second Personal Pronouns

\begin{tabular}{lll}
\hline & Retrieval Items & Frequency \\
\hline 1 & You & 216 \\
2 & Your & 117 \\
\hline
\end{tabular}

With a feature of education authority, declarative sentences are universally applied in instrumental texts, especially imperative sentences to show the direction and restriction from educators to students. Imperative sentences with a hard status imply that educators are the center of transferring knowledge, for example, listen to the talk and check your answers. Compared with imperative sentences, the sentences with "you think / your answers provide students with opportunities to think and choose independently. Second personal pronoun can make readers or listeners involve highly and personally (Biber, 1989). The highly frequent use of second personal pronouns is helpful to imitate the relationship between learners and teaching materials. From table III, it can be seen that "you" and "your" are highly common used in instrumental texts, which shows that Market Leader is a highly learners-centered book. 
The author made a further study of the concordance of "your", finding that the words following "your" are relative to business, like "company, negotiation, rivals, customers, which properly accords with the contents of Market Leader.

Table 4. Retrieval Frequency of Modal Verbs

\begin{tabular}{lll}
\hline & Retrieval Items & Frequency \\
\hline 1 & Would & 40 \\
2 & Can & 26 \\
3 & Will & 24 \\
4 & Should | Ought to & 17 \\
5 & Could & 16 \\
6 & May & 7 \\
7 & Might & 5 \\
8 & Must & 4 \\
9 & Shall & 0 \\
\hline
\end{tabular}

Tomlinson (2013) claimed that most instrumental texts are indifferent and imperative, which matched with the traditional teaching styles. Tomlinson took the view that negotiating and suggested tone should be applied in designing instrumental texts to motivate students' enthusiasm for study. Strong modal verbs include must, should, ought to and shall; weak modal verbs include can, could, will, would, may and might. According to table IV, "would, can and will" rank the first, the second and the third separately. "Would, can and will" belong to weak modal verbs, which reveal the attitude of equal communication with learners in instrumental texts. In addition, in the concordance of modal verbs, the typical word clusters include "may/can you, you can/may/would/might, as you can to give some suggestions to students and ask students that whether they can finish the task.

\subsection{Situation Creation}

Situational teaching is a very effective teaching method. The application of this method can effectively guarantee the better interaction between students and teachers in class. And the atmosphere in class will be more active during the process (Liang, 2015). Situation creation is shown in instrumental texts can better help teachers to design class activities. $B e$ verbs is the most common mode to describe situations in instrumental texts. $B e$ verbs are seldom used exclusively but usually collocated with other words to create situations Market Leader, for example, "imagine", "pretend", "if", "as if" and "suppose". "Role-play" is frequently used in the creation of situation compared with other verbs.

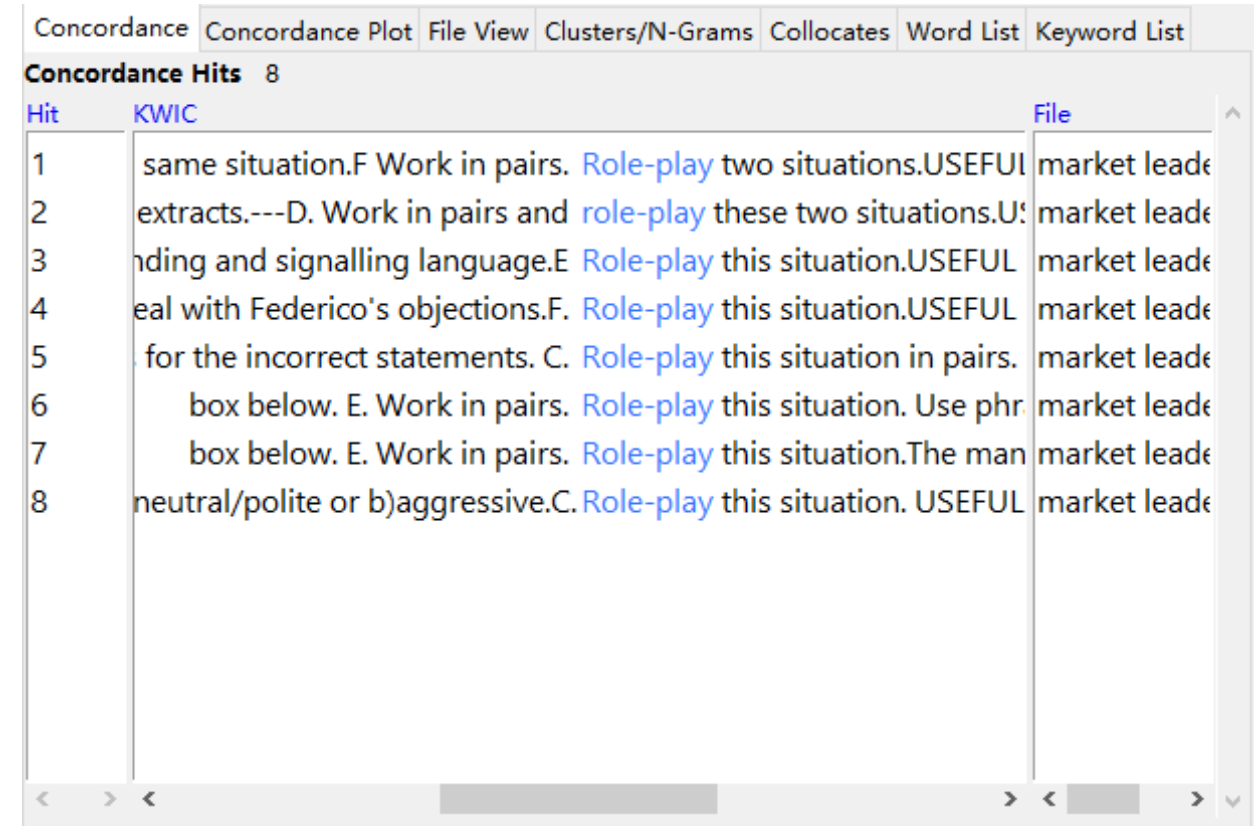

Figure 4. Concordance of ROLE-PLAY 
From Figure 4, "role-play" collocates with "situations". The aim of Market Leader is to cultivate excellent leaders in marketing. Thus, role-play can help students to better experience and practice the role. Comparatively, these activities shown in this book are relatively little, only taking up a small proportion.

In general, instrumental texts in this book fit well with business. And cooperative learning and learners-centered approach are well shown in this book. Cognitive thinking and situation creation are relatively weak in this book. The editors can design more instrumental texts to stimulate students cognitive thinking with the aid of mental words like think, imagine, guess, feel, opinion, believe, change and so on. Situation creation should be paid more attention in this book. Considering Market Leader is a business material, more situation creation activities designed in this book will help students better experience business activities and learn knowledge.

\section{Discussion \& Conclusion}

With the aid of corpus, the instrumental texts in Market Leader are analyzed from the perspective of cognitive strategy, learning styles, the relationship between teaching materials and learners and contextualized language instructions.

On the basis of the above studies, the hypotheses put forward before are verified that the instrumental texts can reflect the teaching notions. And the comprehensive understanding and proper use of the instrumental texts can help to improve the teaching and learning effectiveness. First, cognitive thinking of students can be cultivated through the use of mental words in instrumental texts. However, the number of instrumental texts that can show cognitive activities are relatively small compared with learning styles and relationship between teaching materials and learners. Second, cooperative learning is well shown in this book. In cooperative learning words, "discuss" ranks the first, followed by "group", and "partner" and "pair", which reveals that the activities in this book mainly focuses on multi-person cooperation assisting with pair work. Third, learners-centered approach is applied in the instrumental texts through effective use of second personal pronoun "you" and modal verbs. Finally, situation creation teaching idea is also shown in this book, but it does not stand out compared with the other three teaching notions.

In general, Market Leader can motivate the learners cognitive thinking, cultivate students' cooperative learning ability, putting learners at the first place and helping to create simulated situations. However, the activities referring to cognitive strategies and situation creation are relatively less, which are not adequate for motivating learners.

Limitations of the study should be acknowledged, which provides opportunities for future study. The corpus of the paper only covers book. Comparative study can be done in the future study.

\section{References}

Anderson, L. (2009). A Taxonomy for Learning, Teaching, and Assessing - A review of Bloom's Taxonomy of Educational Objectives. Bejing: Foreign Language Teaching and Research Press.

Biber, D. (1988). Variation across Speech and Writing. Cambridge: Cambridge University Press, 1988. https://doi.org/10.1017/CBO9780511621024

Bonk, C. J., \& King, K. S. (2012). Searching for learner-centered, constructivist, and sociocultural components of collaborative educational learning tools (pp. 25-50). Routledge.

Chen, W. Y. (2010). Interpretation of new teaching concept from pragmatic presupposition of instrumental texts in textbooks. The South of China Today, 02, 27-28.

Conrad, S. (2002). Corpus Linguistics Approach for Discourse Analysis. Annual Review of Applied Linguistics, 22, 75 -95. https://doi.org/10.1017/S0267190502000041

Ellis, R. (2010). Second language acquisition research and language-teaching material, in N. Harwood (ed.), English Language Teaching Materials: Theory and Practice. Cambridge: Cambridge University Press.

Forehand, M. (2010). Bloom's taxonomy. Emerging perspectives on learning, teaching, and technology, 41, 47.

He, A. P. (2007). Corpus-based Analysis on EFL Textbooks. Curriculum, Teaching Material and Method, 27(3), 44-49.

He, A. P., \& Huang X. M. (2011). An Exploration of Stance Markers in EFL Textbooks. Contemporary Foreign Languages Studies, 3, 10-16.

Hewings, M. (2012). Using corpora in research, teaching, and materials design for esp: an evaluation. Taiwan International Esp Journal, 4(1), 1-24. https://doi.org/ 10.6706/TIESPJ.2012.4.1.1 
Hutchinson, T., \&Waters, A. (1984). Interface: English for Technical Communication. London: Longman.

Johnson, D. W., \& Johnson, R. T. (2009). An educational psychology success story: Social interdependence theory and cooperative learning. Educational researcher, 38(5), 365-379. https://doi.org/10.3102/0013189X09339057

Krathwohl, D. R. (2002). A Revision of Bloom' s Taxonomy: An Overview. Theory into Practice, 41(4), 212-218. https://doi.org/10.1207/s15430421tip4104_2

Liang, Z. Q. (2015). On the application of situation creation approach in primary school chinese teaching. Science Education Article Collects, 105-106.

Ljung, M. (1990). A Study of TEFL Vocabulary. Sweden: Graphic Systems AB, Stockholm.

Mukundan, J., \& Ahour, T. (2010). A Review of Textbook Evaluation Checklists across Four Decades (1970-2008). Research for materials development in language learning: Evidence for best practice, 336-349.

Sharan, S. (1990). Cooperative learning: Theory and research. Praeger Publishers.

Tomlinson, B., (2013). Materials Development in Language Teaching. Cambridge: Cambridge University Press.

Wang, X. M., \& Yang, Y. J. (2012). Research and Design of English Textbook Evaluation Based on Readability and FAHP. Foreign Studies in China, 9(03), 67-77. https://doi.org/10.13564/j.cnki.issn.1672-9382.2012.03.011

Zhao, Y., \& Zheng, S. T. (2006). A theoretical analysis of several western textbook evaluation systems and their implications for the college english textbook evaluation in china. Foreign Language Education, 03, 39-45. https://doi.org/ 10.16362/j.cnki.cn61-1023/h.2006.03.013

\section{Copyrights}

Copyright for this article is retained by the author(s), with first publication rights granted to the journal.

This is an open-access article distributed under the terms and conditions of the Creative Commons Attribution license (http://creativecommons.org/licenses/by/4.0/). 